\title{
Canada must find ways to better use health innovations, says new CIHR scientific director
}

\author{
Cite as: CMAJ 2018 November 26;190:E1400-1. doi: 10.1503/cmaj.109-5683
}

Posted on cmajnews.com on Nov. 8, 2018.

$\mathbf{T}$ he goal he cites is at once simple and so very complex: to make things better. Dr. Rick Glazier doesn't officially move into his new role as scientific director of the Institute of Health Services and Policy Research (IHSPR) at the Canadian Institutes of Health Research (CIHR) until January 2019, but he has already spent a career with this multifaceted goal in mind - and a career thinking about how best to get there.

Generating great research is key, he says, but equally important is using that research more effectively and quickly to come up with better ways to apply sound evidence to improve health and health care across the country.

"I think we're great at understanding where research excellence is and supporting that, but I think too often we do the project, learn the lessons, and move onto the next one," says Glazier. He'd like to see more acknowledgement of implementation science - understanding how to take a valuable finding or innovation and get it successfully implemented across regions with very diverse populations and needs. "We need to understand how to use our innovations better."

The breadth of his new role is daunting, but Glazier is very familiar with the work of CIHR and is confident of the robustness of the organization, having supported CIHR as a member of an Institute Advisory Board and as a College of Reviewers Chair, a role that allowed him to provide guidance on strengthening peer review. He's also a researcher, a family physician at St. Michael's Hospital in Toronto, and a professor at the University of Toronto in the Department of Family and Community Medicine and at the Dalla Lana School of Public Health.

As a scientist, Glazier's research interests include evaluating health system transformation, primary care health services delivery models, health of disadvantaged populations, management of chronic conditions, and population-based and geographic methods for improving equity in health.

As a family physician, he's interested in seeing IHSPR find the best ways to engage the public, patients and communities in the work the institute does. "The people who are using the health care system should have a big say in where we set our priorities and how we go about doing our research in an engaged way." He points to SPOR - the Strategy for Patient-Oriented Research - a major CIHR initiative focused on patient engagement, as an example. "For me, that'll be a new direction for IHSPR, but not for CIHR, which has been doing this for many years."

In the short term, though, Glazier says he'll be doing a whole lot of listening. His commitment as scientific director is four years, a term that's renewable for four more. "The whole time will be careful listening, but the first year or two will be especially careful listening around how people are seeing the challenges: What are the highest priorities? What are the gaps? Where do we need to make investments?"

As IHSPR scientific director, he'll also be working closely with CIHR's 12 fellow institutes to determine where to make strategic investments. "The biggest challenge of the job, but also the biggest reward down the road, will come from working with my colleagues and partners to see where can we pool our resources." Those resources will be further boosted through partnerships with federal, provincial, and private funding.

Asked what the future may hold, Glazier sees researchers looking at the system's "pain points," using new information, data, and capacities to help improve wait times and referrals. Other pain points he identifies include mental health and addiction, access to specialty 
care, transitions in care, and big policy developments around the medicare system and what it should cover.

And lurking behind all of IHSPR's planning and goal setting? Technology and how it might change health care delivery over the next 20-30 years. Technological advancement is an unstoppable force, but consideration must be given to unfolding it in a way that supports citizens' health rather than undermines it.

Glazier says that even as he takes on the scientific director role with pages and pages of ideas and plans, he is conscious to approach the task with humility. As much as many researchers wish that they could transform health care through research alone, policies only partially rely on evidence. Politics, policies, and priorities all come into play in the interpretation and application of data. "But when you put all the elements together - information and policy and analysis and practice - you can have a significant impact."

Sarah Brown, Ottawa, Ont. 